\title{
Influence of Workpiece Tilting Angle on Joint Properties in Tailor Friction Stir Welded Blanks of Aluminium Alloy 5052-H32
}

\author{
Chan-Seung Ro*, Hee-Seon Bang**, $\uparrow$, Han-Sur Bang**, Seung-Ji Yoo***, Jong-Hee Kim***, \\ and Eun-Gyeol Choi*** \\ *Dept. of Mechanics, Chosun College of Science \& Technology, GwangJu, 61453, Korea \\ **Dept. of Welding and Joining Science Engineering, Chosun University, GwangJu, 61452, Korea \\ ***Dept. of Welding and Joining Science Engineering, Graduate School, Chosun University, \\ GwangJu, 61452, Korea
}

†Corresponding author : banghs@chosun.ac.kr

(Received September 17, 2018 ; Revised October 1, 2018 ; Accepted October 16, 2018)

\begin{abstract}
The application of aluminium tailor-welded blanks (TWB) is progressively increasing in automotive industries due to its high strength to weight ratio, superior corrosion resistance and crashworthiness. The weldments produced by Friction stir welding (FSW) retains high strength and formability as the process yields the sound joints at relatively lower temperatures in comparison to that of the conventional fusion welding processes. However, the FSW of aluminium alloy of different thicknesses in butt configuration is rarely studied. The primary objective of the present work is to investigate the feasibility of FSW process in joining of 1.5 to $2.5 \mathrm{~mm}$ thick AA5052 alloy tailored blank by tilting the workpiece with respect to machine bed. The effects of workpiece tilting angle with welding and rotational speeds on mechanical and metallurgical properties of the joints are studied. Minimum effective sheet thickness is found to be around $1.34 \mathrm{~mm}$ for tool rotational speed of $400 \mathrm{rpm}$ and tilting angle of $0^{\circ}$. The highest joint strength around $212.6 \mathrm{MPa}(95 \%$ of base metal strength) is achieved at a workpiece tilt angle of $1^{\circ}$ for rotational and travel speed of $400 \mathrm{rpm}$ and $1 \mathrm{~mm} / \mathrm{s}$, respectively. The maximum measured hardness is $60 \mathrm{Hv}$ at tool roational speed of $400 \mathrm{rpm}$ with tilting angle of $1^{\circ}$.
\end{abstract}

Key Words : Friction Stir Welding (FSW), Aluminium alloy, Tailor welded blank

\section{Introduction}

Tailor welded blanks (TWB) are an assembly of sheet metals manufactured by joining similar or dissimilar materials of same or different thickness ${ }^{1-3)}$. The TWB offers a reduction in the overall weight of the structure. TWBs cut the manufacturing cost of the components panel through an optimal distribution of material in an assembly, such as employing stronger materials at highly stressed region while thinner sheets at the lower stress section ${ }^{4}$. As a result, the properties of the blank is tailored to meet the requirement of component's structural integrity, strength and stiffness ${ }^{4}$. The use of aluminium TWBs has gained popularity in the automotive sectors as aluminium offers a considerable weight reduction which in turn improves the fuel efficiency ${ }^{1,5)}$.
However, fusion welding of aluminium alloys of different thicknesses possesses several challenges such as porosity and hot cracking in the weld metal, severe distortion, and the development of refractory oxide layer on surface ${ }^{4-6)}$. Further, the high reflectivity of aluminium makes the process unstable ${ }^{4-6)}$. The Friction stir welding (FSW) is a solid-state welding process that can be used as a recourse to overcome the difficulties in fusion welding of aluminium alloys ${ }^{4}$.

The reported studies on tailored welding of similar or dissimilar aluminium alloys of different thickness by FSW process are limited in the literature ${ }^{1-10)}$. Tavares et al. (2013) reported that the FSW improved the mechanical properties of the TWB made by different thicknesses of AA2198 to achieve the lighter structures ${ }^{7)}$. Zadpoor et al. $(2008,2010)$ found that the joint strength in friction stir welded blanks of AA2024 and AA7075 
decreased with increase in plate thickness from 1.2 to $2.5 \mathrm{~mm}^{2,3}$. Sheikhi et al. (2007) studied the effect of process parameters and tool geometry on mechanical properties of friction stir welded tailor blanks of AA6181 with thickness combination of 1 to $2 \mathrm{~mm}^{4}$. The authors obtained satisfactory surface finish with a maximum joint strength of around 91 to $99 \%$ of the base metal strength. In another study, Bonoome et al. (2007) achieved sound and defect free joint in friction stir butt welding of AA5754 and AA6181 with different thicknesses of 1 and $1.5 \mathrm{~mm}^{1)}$. Fartini et al. (2007) investigated the influence of tool tilting angle on the mechanical strength of AA7075 TWB with thicknesses of 1 and $2 \mathrm{~mm}$ and found the maximum joint strength of $80 \%$ of the parent metal ultimate tensile strength ${ }^{8)}$. Sahu et al. (2017) found maximum joint strength around 99\% of the base metal using tilted machine bed in joining AA1050 alloy by FSW with workpiece thickness ratios of $1.33,1.67$ and $2^{9)}$. In another study, Nadikudi et al. (2015) investigated the formability of TWB of AA6061 and AA2014 made by FSW using five different tool pin profiles $^{10)}$. The authors found the blank prepared by a square pin provided better formability in comparison to the other tool pin profiles. The reported experimental studies provide an insight of FSW of different thickness aluminium alloys. However, the effect of workpiece tilting angle in joining of varying thicknesses aluminium alloys by FSW process is few in the literature.

The present work reports the feasibility to join different thicknesses AA5052-H32 in butt configuration using FSW process by tilting the bottom surface of the workpiece. Further, an attempt is undertaken to study the influence of varying workpiece tilting angle and process parameters on mechanical properties of the weld.

\section{Experimental Details}

The AA5052-H32 of thicknesses 1.5 and $2.5 \mathrm{~mm}$ was selected as a base material. Table 1 shows the chemical composition and mechanical properties of the base material. A typical gantry type FSW machine was em-

Table 1 Chemical compositions of the base material

\begin{tabular}{|c|c|c|c|c|c|c|c|c|}
\hline Material & $\begin{array}{c}\mathrm{Si} \\
(\%)\end{array}$ & $\begin{array}{c}\mathrm{Fe} \\
(\%)\end{array}$ & $\begin{array}{c}\mathrm{Cu} \\
(\%)\end{array}$ & $\begin{array}{c}\mathrm{Mn} \\
(\%)\end{array}$ & $\begin{array}{c}\mathrm{Mg} \\
(\%)\end{array}$ & $\begin{array}{c}\mathrm{Ti} \\
(\%)\end{array}$ & $\begin{array}{c}\mathrm{Cr} \\
(\%)\end{array}$ & $\begin{array}{c}\mathrm{Al} \\
(\%)\end{array}$ \\
\hline AA5052-H32 & 0.08 & 0.21 & 0.019 & 0.01 & 2.34 & 0.01 & 0.1 & Bal. \\
\hline
\end{tabular}

Table 2 Mechanical properties of the base material

\begin{tabular}{|c|c|c|c|}
\hline Material & $\begin{array}{c}\text { Yield strength } \\
(\mathrm{MPa})\end{array}$ & $\begin{array}{c}\text { Tensile strength } \\
(\mathrm{MPa})\end{array}$ & $\begin{array}{c}\text { Elongation } \\
(\%)\end{array}$ \\
\hline AA5052-H32 & 188 & 225 & 12 \\
\hline
\end{tabular}

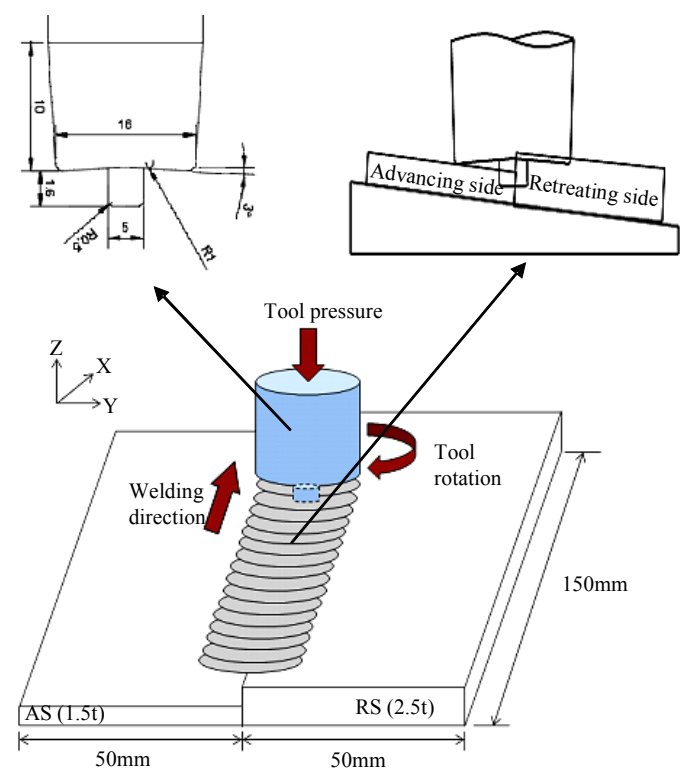

Fig. 1 Schematic diagram of experimental setup

Table 3 FSW tool dimension

\begin{tabular}{|c|c|c|c|}
\hline $\begin{array}{c}\text { Shoulder } \\
\text { diameter }(\mathrm{mm})\end{array}$ & $\begin{array}{c}\text { Shoulder } \\
\text { shape }\end{array}$ & $\begin{array}{c}\text { Pin length } \\
(\mathrm{mm})\end{array}$ & $\begin{array}{c}\text { Pin diameter } \\
(\mathrm{mm})\end{array}$ \\
\hline 16 & Cylinder & 1.6 & 5 \\
\hline
\end{tabular}

Table 4 Processing conditions used for FSW of AA5052H32 alloy

\begin{tabular}{|c|c|c|c|}
\hline $\begin{array}{c}\text { Rotation speed } \\
(\mathrm{rpm})\end{array}$ & $\begin{array}{c}\text { Welding speed } \\
(\mathrm{mm} / \mathrm{s})\end{array}$ & $\begin{array}{c}\text { Workpiece } \\
\text { tilting angle }\left({ }^{\circ}\right)\end{array}$ & $\begin{array}{c}\text { Plunge } \\
\text { depth }(\mathrm{mm})\end{array}$ \\
\hline $400 \sim 600$ & 1 & 0 & 0.9 \\
\cline { 2 - 4 } & 1 & 1 & 0.9 \\
\hline
\end{tabular}

ployed to join the base materials in butt configuration using WC-12\% Co made cylindrical tool. Table 2 shows the tool dimensions. The angle between the machine bed and bottom surface of plates (the rotation angle of the workpiece) was varied from 0 and $1^{\circ}$. The thinner plate was placed on advancing side and thicker plate on the retreating side. Fig. 1 shows the schematic diagram of the detailed experimental setup. The tool was set at a tilt angle of $2^{\circ}$ with the vertical axis in the direction of welding. Table 3 depicts the welding conditions that are used for the experiments. The welding conditions were selected based on several trial experiments after achieving a continuous bead profile without crack under visual inspection. The cross-section of the bead was measured after polishing and etching with Keller's reagent. A universal testing machine (Shimadzu: EHF-EF200kN, Hydraulic type) was employed to evaluate of the joint strength of the specimen at a crosshead speed of 1 
$\mathrm{mm} / \mathrm{min}$ as per ISO 6892-1:2016 standard. The Vickers micro-hardness was measured along the joint cross-section at the mid-thickness of the thinner plate. The Erichsen cupping test (Smtest in Korea: SMB-006-30T) was carried out based on ASTM 643-09 standard to evaluate the formability of joints using $10 \mathrm{~mm}$ punch tip at a speed of $20 \mathrm{~mm} / \mathrm{min}$.

\section{Results and Discussion}

\subsection{Bead Profile}

Fig. 2 shows the weld bead profiles and corresponding cross-sectional macrograph in joining of 1.5 to $2.5 \mathrm{~mm}$ thick AA5052-H32 at a rotational speed of 400 to 600 rpm for different combinations of workpiece tilting angle. Continuous beads were formed for all welding conditions. Fig. 2 illustrates the volume of burr in the retreating side for all welding condition. An increase in tilt angle leads to reduce difference of thickness between two materials. Therefore, plunge depth of FSW tool pin into the workpiece is increase, which lead to increase the flow of material. The yellow boxes in Fig. 2 show no bonding between the workpiece at the bottom side of the workpiece. That can be attributed to the insufficient plastic flow due to frictional heat and in sufficient pressing force due to the small contact area of the tool shoulder with the material surface. Fig. 2 shows the presence of joint line in the weld zone (white line), which is scattered oxide particles originated from the aluminium surface. Several authors reported that presence of joint line technical term had no detrimental effect on joint mechanical strength ${ }^{11,12)}$.

\subsection{Effective Sheet Thickness}

The minimum bonding distance from top surface of the plate along thickness direction is called the effective sheet thickness. The effective sheet thicknesses (red line) were measured from cross-sectional bead profiles in Fig. 2. Fig. 3 shows the measured effective sheet thickness at different workpiece tilting angles for three tool rotational speeds of 400 to $600 \mathrm{rpm}$. The effective sheet thicknesses increased with increasing tilting angle at any rotational speeds of 400 to $600 \mathrm{rpm}$. As the tilting angle increases, the plastic flow becomes more acltive, the effective sheet thickness increases because the base material is sufficiently softened due to the increased heat input and the plastic flow of the material is more easily caused by the increase of the agitating

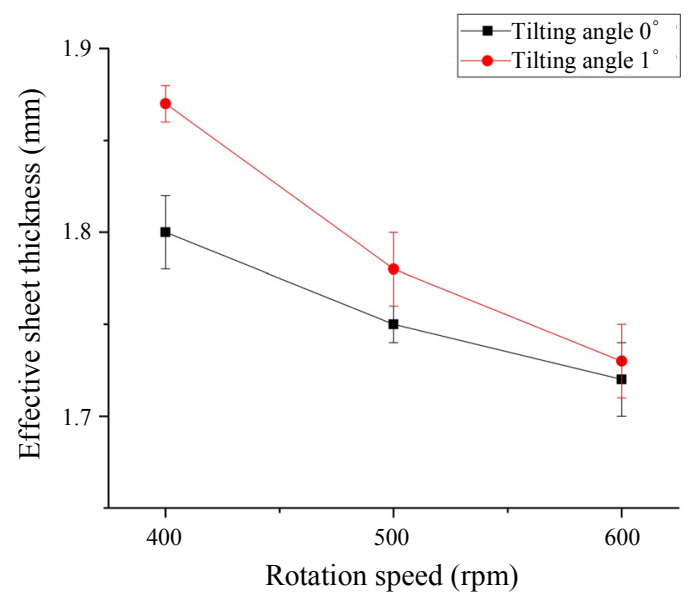

Fig. 3 Effective sheet thickness at different workpiece tilting angles for tool rotational speeds of 400, 500, $600 \mathrm{rpm}$

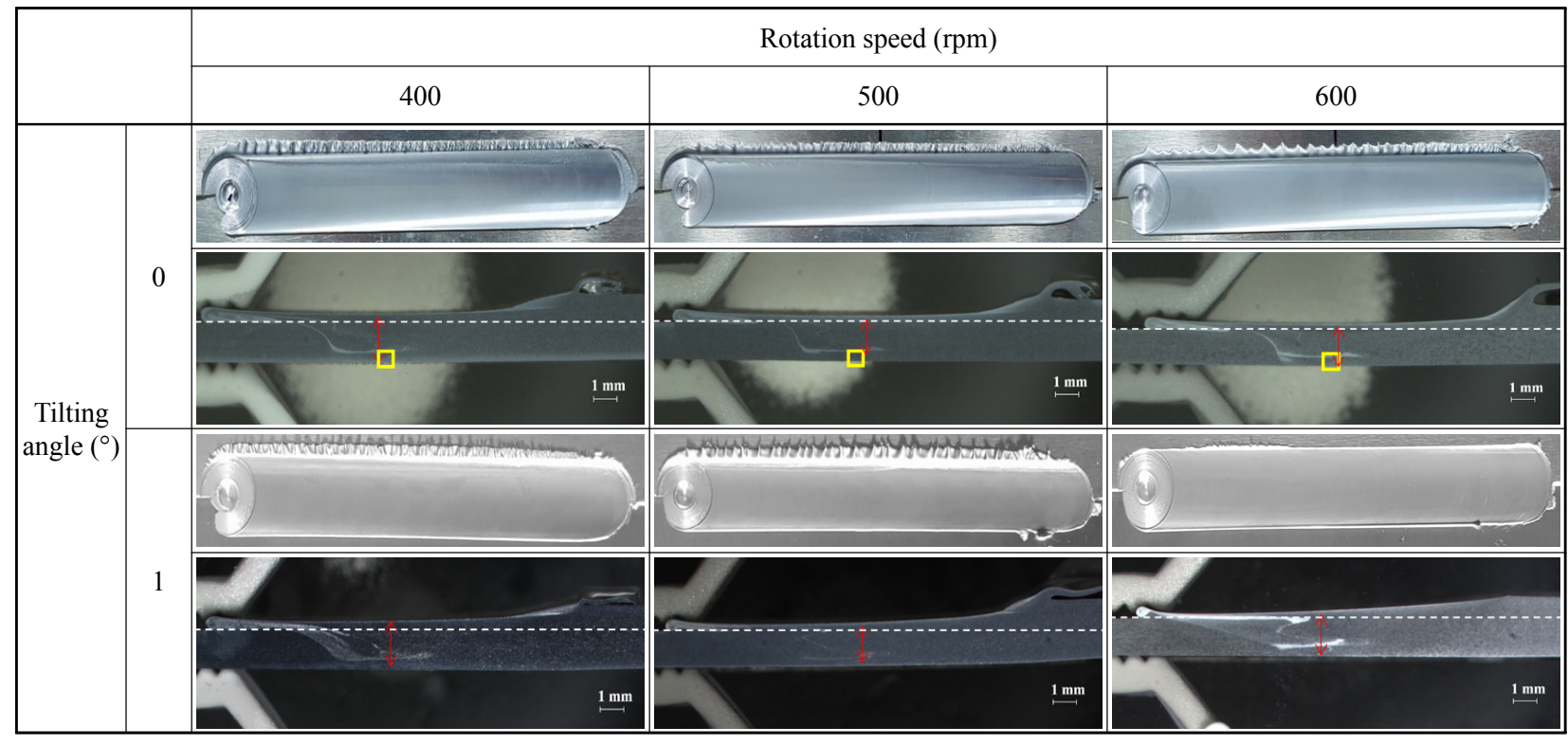

Fig. 2 Weld bead profiles and corresponding cross-sectional macrographs at tilting angle of 0 and $1^{\circ}$ 
force. It is considered that the effective sheet thickness should be controlled by controlling the bonding type and the bonding condition so that the thickness of the effective sheet thickness can be secured.

\subsection{Tensile Strength}

This study investigated the butt - welding friction stir welding of aluminium alloy AA5052-H32. The tensile test was carried out in a direction perpendicular to the weld line, and three specimens were prepared for each condition. Fig. 4 shows the results of the tensile test for differnt rotational speed and tilting angle. The tensile strength was expressed as the average value of the three test samples.

The lowest tensile strength of (193.7 MPa) (86\% compared to the base material) was observed for a rotational speed of $600 \mathrm{rpm}$ and a tilting angle $0^{\circ}$. That can be attributed to reduction of effective sheet thickness of the welded part during welding.

Tensile test results showed that rotation speed of 400 $\mathrm{rpm}$, the maximum tensile strength of $212.6 \mathrm{MPa}$ was obtained for tilting angle of $1^{\circ}$, and fracture occurred in the base material (BM) of $1.5 \mathrm{t}$ plate. Fig. 5 shows Facture tensile specimen at a rotational speed of 400 rpm and workpiece tilting angle of $1^{\circ}$. It could be noted that the strength was $95 \%$ of the ultimate tensile strength of AA5052-H32. The tensile strength at a rotational speed of $600 \mathrm{rpm}$ showed lower strength as compared

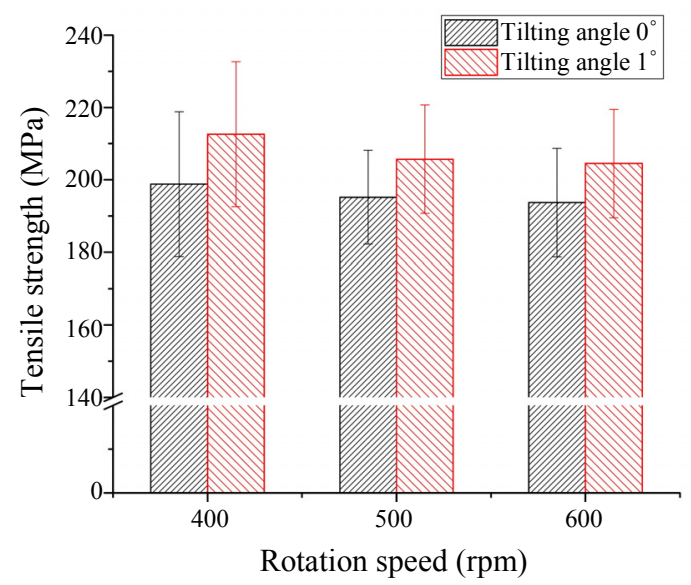

Fig. 4 Tensile strength at different workpiece tilting angles for tool rotational speeds of 400,500, $600 \mathrm{rpm}$

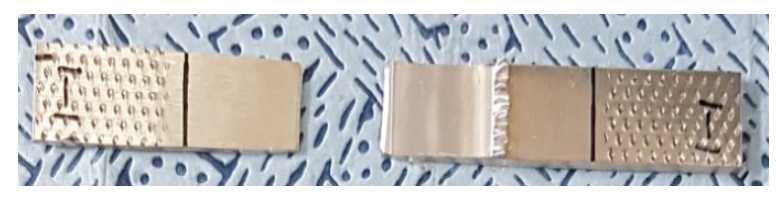

Fig. 5 Fracture tensile specimen at a rotational speed of $400 \mathrm{rpm}$ and workpiece tilting angle of $1^{\circ}$ to that of $400 \mathrm{rpm}$. This is because the thickness of the welded part is decreased due to the thinning effect at heat input. The rotation speed of $400 \mathrm{rpm}$ is considered to be a better condition as it shows a relatively high tensile strength than that of $600 \mathrm{rpm}$.

\subsection{Hardness Distribution}

Fig. 6 shows the hardness of the specimens with the highest tensile strength at a rotational speed of $400 \mathrm{rpm}$. The hardness was measured in the advancing side and retreating side at a position of the middle line and 0.5 mm away from the center. Hardness distribution of the test specimen showed that the hardness value tended to derease from the base material to the welds. The average hardness values were AA5052-H32 alloy were $69.4 \mathrm{Hv}$ for $2.5 \mathrm{~mm}$ and $68.4 \mathrm{Hv}$ for $1.5 \mathrm{~mm}$, respectively. The hardness distribution value in the heat affected zone (HAZ) was about $54 \mathrm{Hv}$ and the thermo-mechanical affected zone (TMAZ) was about $50 \mathrm{Hv}$ in $1.5 \mathrm{~mm}$ of thin plate. The hardness distribution values of the HAZ
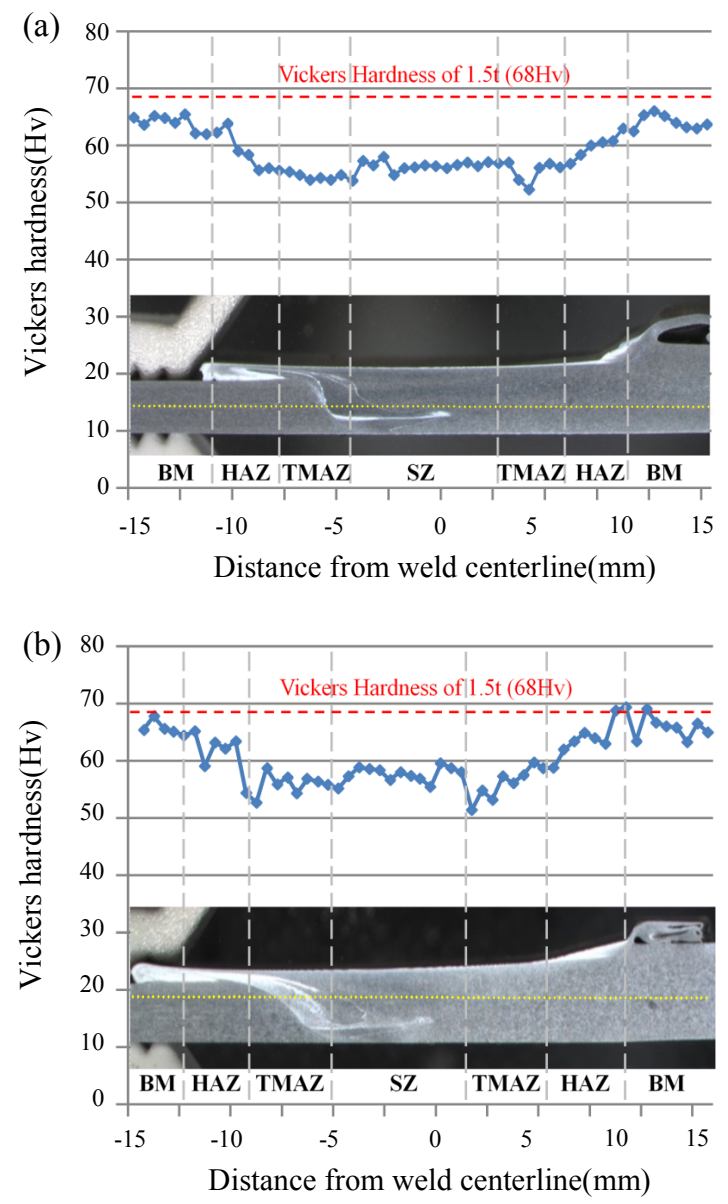

Fig. 6 Distribution of micro-hardness along the weld transverse section for FSW of AA5052-H32 alloy at a constant workpiece rotational speeds of 400 for different tilting angle of (a) $0^{\circ}$ (b) $1^{\circ}$ 
and TMAZ in $2.5 \mathrm{~mm}$ thickness plate were measured as $61 \mathrm{Hv}$ and $56 \mathrm{Hv}$, respectively. The maximum hardness value in the stir zone (SZ) was $63 \mathrm{Hv}$. Re- gardless of the plate thickness, hardness of the HAZ tended to be decreased sharply compared to that of the base material. The hardness of the SZ was lower than that of the base material. In addition, the hardness values of the welds tended to be lower than those of the base materials under all conditions. The maximum hardness value of the welds was $60 \mathrm{Hv}$ for rotational speed of $400 \mathrm{rpm}$ with tilting angle of $1^{\circ}$. The average hardness of SZ was measured as $59 \mathrm{Hv}$. The measured hardness of HAZ, TMAZ were lower than that of the base material.

This is because an increase in dynamic recrystallization leads to reduce hardness value, and decrease in dislocation density in HAZ and TMAZ increase dynamic recrystallization ${ }^{17)}$.

\subsection{Erichsen Cupping Test}

Fig. 7 shows the erichsen cupping test of the specimens with the highest tensile strength at a rotational speed of $400 \mathrm{rpm}$. Fracture load and displacement of erichsen test sample produced at $400 \mathrm{rpm}$ and tilting angle of $0^{\circ}$ were $12.7 \mathrm{kN}$ and $11.0 \mathrm{~mm}$, respectively. Likely, fracture load and displacement of erichsen test sample produced at $400 \mathrm{rpm}$ and $1^{\circ}$ were $13.6 \mathrm{kN}$ and $12.6 \mathrm{~mm}$, respectively. The fracture load and displacement on erichsen test sample of $1^{\circ}$ was higher than that of test sample of $0^{\circ}$. The hardness distribution of the TMAZ showed lower value than that of the other parts due to softening effect. Moreover, cracks were formed in TMAZ as a result of Erichsen cupping test. This result shows the good agreement with hardness distribution.

\section{Conclusions}

The following conclusions are derived from the present work:

1) No bonding is observed at the bottom side at tilting angle of $0^{\circ}$. It is believed that this is caused by insufficient plastic flow due to difference of thickness between two materials.
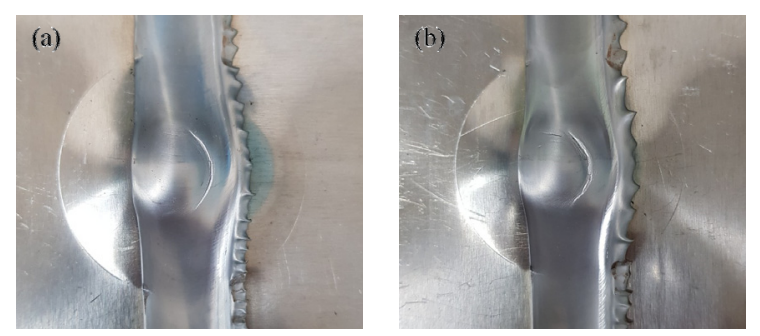

Fig. 7 Macrograph of FSWelds after Erichsen cupping test (a) Tilting angle $0^{\circ}$, (b) Tilting angle $1^{\circ}$
2) In the case of tilting angle $1^{\circ}$, the pin is inserted at the interface of the welded part to ensure smooth plastic flow.

3) The effective sheet thickness at tilting angle of $1^{\circ}$ was thicker than that of tilting angle at $0^{\circ}$. The maximum thickness was $1.66 \mathrm{~mm}$ at tilting angle of $1^{\circ}$ with rotational speed of $400 \mathrm{rpm}$.

4) The maximum joint strength is found to be around 212.6 $\mathrm{MPa}$ corresponding to rotational speed of 400 rpm and workpiece tilting of $1^{\circ}$.

5) The maximum hardness value at tilting angle of $1^{\circ}$ with rotational speed of $400 \mathrm{rpm}$ were $60 \mathrm{Hv}$, which were $88 \%$ of the base material hardness. This is because the dislocation density decreases and dynamc recrystallization increases.

\section{Acknowledgement}

This research was supported by Basic Science Research Program through the National Research Foundation of Korea (NRF) funded by the Ministry of Education (2016R1D1A3B03935978).

ORCID: ChanSeung Ro: https://orcid.org/0000-0002-7346-0281 ORCID: HeeSeon Bang: https://orcid.org/0000-0003-4891-5712

\section{References}

1. Golden berg, A.A., Bazerghi, A., Preview approach to force control of robot manipulators, J. Appl. Mech. 20 (5) (1985), 449-464 https://doi.org/10.1016/0094-114X(85)90049-7

2. Zadpoor, A.A., Sinke, J., Benedictus, R., Global and Local Mechanical Properties and Microstructure of Friction Stir Welds with Dissimilar Materials and/or Thicknesses, Metall. Mater. Trans. A., 41A (2010), 3365-3378 https://doi.org/10.1007/s11661-010-0403-3

3. Zadpoor, A.A., Sinke, J., Benedictus, R., The Effects of Friction Stir Welding on the Mechanical Properties and Microstructure of 7000 Series Aluminium Tailor-Welded Blanks, Int. J. Mater. Form., 1 (2008), 1311-1314 https://doi.org/10.1007/s12289-008-0144-7

4. Sheikhi, S., dos Santos, J.F., Effect of Process Parameter on Mechanical Properties of Friction Stir Welded Tailored Blanks from Aluminium Alloy 6181-T4, Sci. Technol. Weld. Joi., 12 (2007), 370-375

https://doi.org/10.1179/174329307X173698

5. Davies, R.W., Oliver, H.E., Smith, M.T., Grant, G.J., Characterising Al Tailor Welded Blanks for Automotive Applications, Jom-J. Min. Met. Mat. S., 51 (1999), 46-50 https://doi.org/10.1007/s11837-999-0222-4

6. Davis, J.R., Aluminium and aluminium alloy, ASM International, Materials Park, Ohio, USA, 5th Edition, (1994).

7. Tavares, S.M.O, dos Santos, J.F., de Castro, P.M.S.T., Friction Stir Welded Joints of Al-Li Alloys for Aero- 
nautical Applications: Butt Joints and Tailor Welded Blanks, Theor. Appl. Fract. Mech., 65 (2013), 8-13 https://doi.org/10.1016/j.tafmec.2013.05.002

8. Fratini, L., Buffa, G., Shivpuri, R., Improving Friction Stir Welding of Blanks of Different Thicknesses, Mater. Sci. Eng. A, 459 (2007), 209-215 https://doi.org/10.1016/j.msea.2007.01.041

9. Sahu, P.K., Pal, S., Mechanical Properties of Dissimilar Thickness Aluminium Alloy by Single/Double Pass FSW, J. Mater. Process. Tech., 243 (2017), 442-455 https://doi.org/10.1016/j.jmatprotec.2017.01.009

10. Nadikudi, B.K.B., Davidson, M.J., Akasapu, N.R., Govindaraju, M., Formability Analysis of Dissimilar Tailor Welded Blanks Welded With Different Tool Pin Profiles, Trans. Nonferrous Met. Soc. China, 25 (2015), 1787- 1793 https://doi.org/10.1016/S1003-6326(15)63784-0

11. Threadgill, P.L., Terminology in Friction Stir Welding, Sci. Technol. Weld. Joi., 12 (2007), 357-360 https://doi.org/10.1179/174329307X197629

12. Threadgill, P.L., Leonard, A.J., Shercliff, H.R., Withers, P.J., Friction Stir Welding of Aluminium Alloys, Int. Mater. Rev., 54 (2009), 49-93 https://doi.org/10.1179/174328009X411136

13. Jayaraman, M., Balasubramanian, V., Effect of process parameters on tensile strength of friction stir welded cast A356 aluminium alloy joints, Trans. Nonferrous
Met. Soc. China, 23 (2013), 605-615

https://doi.org/10.1016/S1003-6326(13)62506-6

14. He, J., Ling, Z., Li, H., Effect of tool rotational speed on residual stress, microstructure, and tensile properties of friction stir welded 6061-T6 Aluminum Alloy Thick Plate, Int. J. Adv. Manuf. Technol., 84 (2016), 19531961

https://doi.org/10.1007/s00170-015-7859-7

15. Tufaro, L.N., Manzoni, I., Svoboda, H.G., Effect of Heat Input on AA5052 Friction Stir Welds Characteristics, Proc. Mat. Sci., 8 (2015), 914-923

https://doi.org/10.1016/j.mspro.2015.04.152

16. Mishra, R.S., Ma, Z.Y., Friction Stir Welding and Processing, Mater. Sci. Eng. R, 50 (2005), 1-78 https://doi.org/10.1016/j.mser.2005.07.001

17. Zhang, Z., Yang, X. Zhang, J., Zhou, G., Xu, X., Zou, B., Effect of welding parameters on microstructure and mechanical properties of friction stir spot welded 5052 aluminum alloy, Mater. Design, 32 (2011), 4461- 4470 https://doi.org/10.1016/j.matdes.2011.03.058

18. El-Sayed, M.M., Shash, A.Y., Rabou, M.A., Influence of the Welding Speeds and Changing the Tool Pin Profiles on the Friction Stir Welded AA5083-O Joints, Journal of Welding and Joining, 35 (2017), 44-51 https://doi.org/10.5781/JWJ.2017.35.3.7 